Available online at www.eccomasproceedia.org

Eccomas Proceedia COMPDYN (2019) 5028-5040

ECCOMAS

Proceedia
COMPDYN 2019

$7^{\text {th }}$ ECCOMAS Thematic Conference on Computational Methods in Structural Dynamics and Earthquake Engineering M. Papadrakakis, M. Fragiadakis (eds.) Crete, Greece, 24-26 June 2019

\title{
A SLAMA-BASED ANALYTICAL PROCEDURE FOR THE COST/PERFORMANCE-BASED EVALUATION OF BUILDINGS
}

\author{
Simona Bianchi ${ }^{1}$, Jonathan Ciurlanti ${ }^{1}$, and Stefano Pampanin ${ }^{1}$ \\ ${ }^{1}$ Sapienza University of Rome \\ Department of Structural and Geotechnical Engineering, Via Eudossiana 18, 00184, Rome, Italy \\ simona.bianchi@uniroma1.it, \\ jonathan.ciurlanti@uniroma1.it, stefano.pampanin@uniroma1.it
}

\begin{abstract}
The decision-making process for seismic risk is affected by the assessment/design procedure adopted and rigorous methodologies have been developed to estimate performance metrics relevant to stakeholders to take informed decisions. Input data for loss estimations of buildings are typically floor accelerations and inter-storey drift ratios, generally obtained from: 1) simplified evaluations, based on linear models and static analysis, 2) more accurate nonlinear static analyses, or 3) more complex and time-consuming non-linear history analyses. Considering that non-linear static analyses are arguably the best compromise between accuracy and simplicity, this paper proposes the application of an analytical non-linear static procedure, based on the Simplified Lateral Mechanism Analysis (SLaMA) of the NZSEE 2017 Guidelines, for the cost/performance-based evaluation of Reinforced Concrete structures. In order to validate the accuracy of the method, multi-storey case-study buildings are analyzed using different structural analysis methods (the proposed SLaMA-based approach vs. numerical Pushover vs. Time-History) and through sophisticated or simplified loss assessment methodologies (FEMA P-58, 2012; D.M. n.65, 2017).

The results in terms of Expected Annual Losses from the SLaMA-based approach are quite satisfactory - increase of 7-18\% or 3-7\% compared to numerical Pushover results from probabilistic or simplified loss estimations, increase of 20-40\% compared to numerical TimeHistory results - and, in general, more accurate than static analyses results, even though no numerical modelling is needed. Therefore, the SLaMA-based method can be a promising tool for a daily use of practicing engineers for a rapid evaluation of economic losses for both the seismic assessment of existing buildings and the initial feasibility studies of new structures.
\end{abstract}

Keywords: Cost/performance-based, SLaMA procedure, Pushover analysis, Time-history analysis, Expected Annual Losses. 


\section{INTRODUCTION}

Seismic design philosophy is based on controlling the building response under low-to-high intensity earthquakes, including either structural and non-structural components. Traditionally the design aimed to prevent the damage of these elements under low-intensity earthquakes, to reach repairable conditions in medium-intensity shakings and to avoid building collapse under high-intensity earthquakes. However, past earthquakes (e.g. Northridge 1994 and Kobe 1995, confirmed by more recent events such as Christchurch earthquake 2010-2011) highlighted very high economic losses in terms of repair costs and business interruption even for codecompliant buildings, leading in the mid-1990s to the development of the performance-based earthquake engineering (PBEE) concept $[1,2]$.

Vision 2000 [3] is one of the first documents where there is evidence of this new philosophy. Different structural and non-structural performance levels at various intensity demands (frequent, occasional, rare, and very rare) are described and classified as fully operational, operational, life safety, and near collapse, thus design objectives for building typologies are identified through the combination of performance levels and seismic hazard. Following this original concept, a series of additional documents were published considering the same design philosophy and representing the first generation of PBEE $[4,5,6]$

Nevertheless, the initial PBEE procedures were deterministic-based and affected by many shortcomings, such as the relations between engineering demand and component performance based on relations measured from laboratory tests or assumed considering engineering judgement [7]. Therefore, a more rigorous and probabilistic methodology was developed by the Pacific Earthquake Engineering Research (PEER) Center and its framework is summarized in Figure 1.

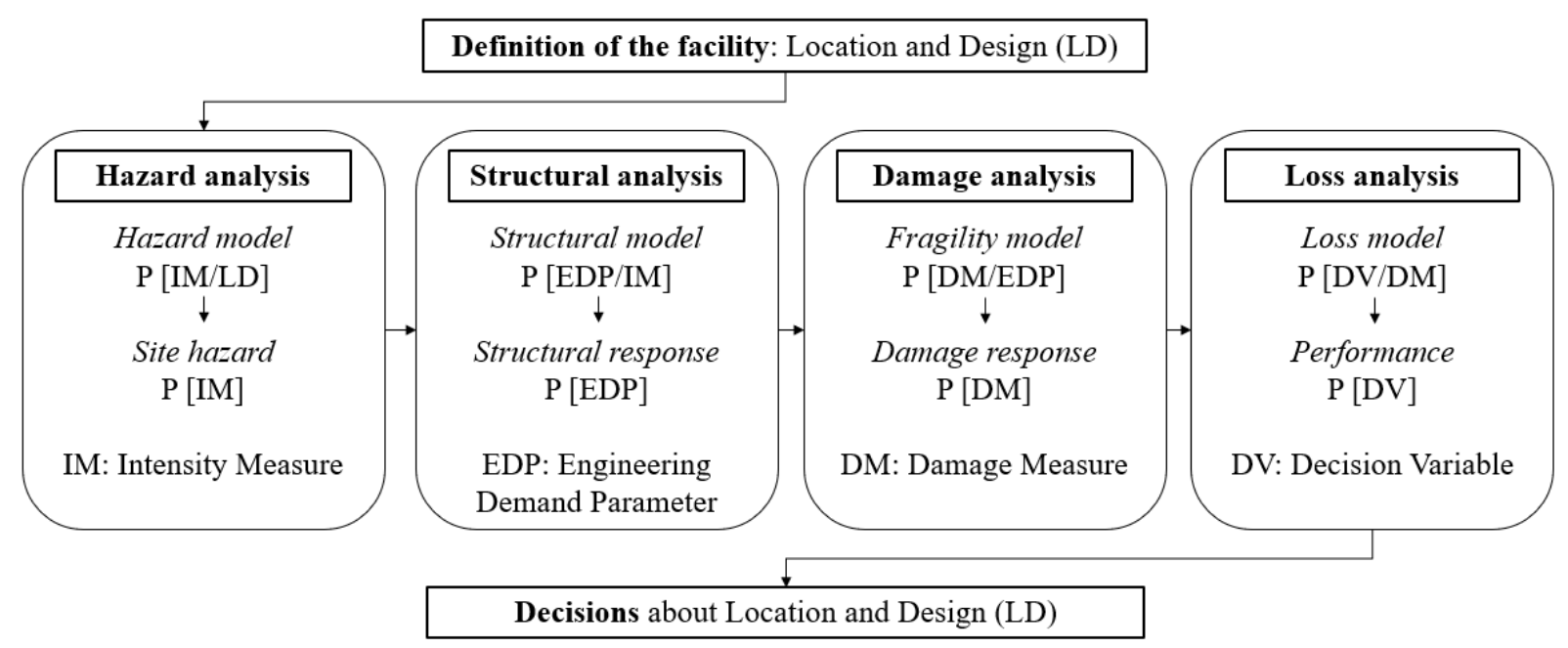

Figure 1: Performance-Based Earthquake Engineering (PBEE) methodology (modified after [8]).

The PEER methodology allows the direct evaluation (estimation) of performance measures such as economic losses, downtime and casualties that are relevant to stakeholders to manage decisions about seismic risk mitigation. The comprehensive framework includes the description, definition and qualification of different variables considering all the inherent uncertainties in the earthquake performance assessment. The process starts with the definition of the ground motion hazard (Intensity Measure) which affects the structural response, then the building structural response can be evaluated in terms of accelerations, deformations or other quantities (Engineering Demand Parameter). Finally, the system response is related to the 
damage of each building component (Damage Measure) and the damage is transformed into quantities useful for decision-making processes (Decision Variable).

For the practical implementation of the probabilistic procedure, the US Federal Emergency Management Agency (FEMA) commissioned to the Applied Technology Council (ATC) the development of an electronic tool to apply this methodology, referred to as Performance Assessment Calculation Tool (PACT) and provided with the publication of the FEMA P-58 Document [9].

The application of the PBEE procedure is primary for the seismic loss evaluation of new buildings as well as for taking decisions on intervention/retrofit strategies of existing structures, particularly in the initial feasibility studies of the building/intervention. However, the fully probabilistic procedure can be time-consuming in its implementation, because it also requires the definition of numerical models to evaluate the building response through non-linear static and dynamic analyses. For this reason, this paper presents the application of an analytical procedure for non-linear static analysis, based on the Simplified Lateral Mechanism Analysis (SLaMA) of the NZSEE 2017 Guidelines, that can be rapidly implemented providing acceptable results for the loss estimation and can thus be a promising tool for a daily use of engineers for a rapid yet quite reliable initial evaluation of the post-earthquake losses.

\section{EVALUATION OF BUILDING RESPONSE}

Structural analysis is conducted to determine the building response to earthquake shaking, obtaining values for those key parameters that are predictive of structural and non-structural damage, such as floor accelerations, floor velocities, story drift ratios and residual drift ratios.

Alternative procedures can be used to estimate the peak values of these parameters: 1) simplified procedures, which consider linear models and static analyses to estimate the lateral yield strength and generate median demand values, thus determining the building response at each floor through simplified and numerically calibrated formulas; 2) non-linear static analyses, which allow the definition of the building capacity curve from numerical modelling as well as the performance points for the various seismic intensity (i.e. Capacity Spectrum Method), giving more accurate predictions than the previous ones; 3) non-linear response (time) history analysis, that is the most sophisticated method, where the structure is numerically modelled in its full non-linear cyclic and dynamic behavior, sets of demand parameters are generated from sets of earthquake input motions and are used to develop statistics (median values and dispersions) for each parameter of interest. Among all the aforementioned analysis methods, the non-linear static procedures (pushover) are the best compromise between accuracy and simplicity.

In the recently developed New Zealand Seismic Assessment Guidelines [10] an analytical non-linear static analysis procedure has been proposed for the seismic assessment of reinforced concrete existing buildings, the Simplified Lateral Mechanism Analysis (SLaMA), that is shown schematically in Figure 2. This assessment method, mandatory for every assessment prior to carry out any numerical modeling, is able to predict the building capacity curve (pushover) through an analytical study that, starting from the local section and member analysis and through the hierarchy of strengths evaluation of subassemblies, evaluate the local and global building mechanisms.

Notwithstanding the SLaMA procedure has been primarily implemented for the assessment existing structures, in this paper the method is applied, for the sake of simplicity, to rapidly estimate the seismic response of new reinforced concrete buildings, because it can be very useful for initial feasibility studies. The proposed simplified loss-assessment method based on a SLaMA approach, can be however used and properly exploited for either assessing existing structures and comparing alternative retrofit strategies. 
In the case of a new building, the procedure can be modified and simplified as follows: 1) in terms of input data, the building characteristics are not already available but obtained from a preliminary building design that aims to already respect the hierarchy of strengths determining a final beam-sidesway mechanism, as required by the seismic codes; 2) the capacity curve of such type of building mechanism is analytically determined considering the results from the section analysis evaluation; 3) finally, introducing the capacity curve into the Acceleration-Displacement Response Spectra and combining it with the demand spectra, the expected maximum accelerations and displacements at different seismic intensities can be determined.

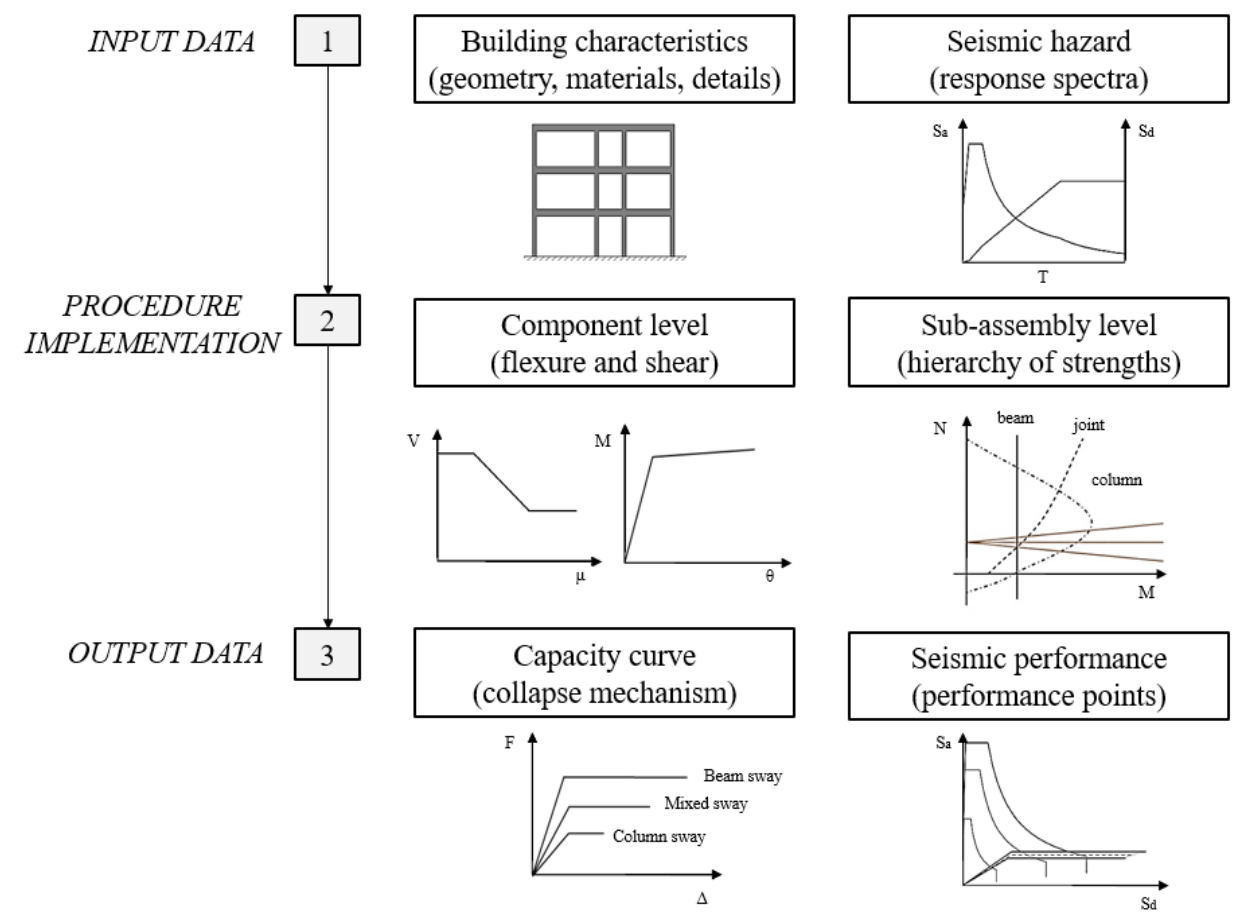

Figure 2: Framework of the SLaMA assessment procedure for reinforced concrete buildings.

\section{RESEARCH MOTIVATION}

In the current international seismic codes, the building design aims to guarantee the LifeSafety performance objective. However, as the reliability of design and construction practice in meeting this goal has improved, there has been an increasing demand for engineers to provide building design capable of reducing both damage and business interruption [11] and new tools able to determine these parameters in the philosophy of the performance-based earthquake engineering have been developed.

Apart from the seismic assessment process of existing buildings, the need for loss estimation in the common design process is starting to spread, therefore practical and efficient tools must be developed to be used by engineers. As alternative to more sophisticated procedures based on non-linear dynamic analyses, as previously described, more rapid estimations of post-earthquake losses can be determined through non-linear static (pushover) evaluations, especially as part of an initial feasibility study of the building design features.

This paper proposes the application of an analytical non-linear static analysis procedure, based on the Simplified Lateral Mechanism Analysis (SLaMA), for a rapid evaluation of postearthquake losses of buildings without the need of more complicated numerical models.

A set of multi-storey case-study buildings is considered to apply and validate the proposed procedure, as described below. 


\section{VALIDATION OF THE SLAMA-BASED ANALYTICAL PROCEDURE}

Cost/performance evaluations are implemented for a set of multi-storey buildings considering different approaches: the proposed SLaMA-based analytical procedure and numerical analyses through both non-linear Push-Over and Time-History analyses.

The numerical investigations are implemented with the aim of validating the analytical approach and confirming whether acceptable results in terms of economic losses can be expected from the SLaMA evaluation when compared to more sophisticated numerical results.

\subsection{Description of the case-study buildings}

The procedure is implemented considering four 5-storeys monolithic reinforced concrete buildings located in a high seismic zone in Italy (Soil type C, PGA of $0.35 \mathrm{~g}$ at the Life-Safety Limit State). The benchmark case-study structure has a plan configuration of $32 \mathrm{~m}$ x $18 \mathrm{~m}$, inter-storey height of $3.8 \mathrm{~m}$; the building has commercial use for the first two floors, residential use for the other two floors, while the top floor is a roof. Lateral resistance against seismic action is provided by two seismic resistant four-bay frames in the longitudinal direction and two shear walls in the transverse direction. The other buildings are derived from the initial case-study structure (Casel) by varying: the beam span length in both seismic directions (Case2); the inter-storey height to $4.5 \mathrm{~m}$ (Case3); both the beam span length and the interstorey height (Case4). Figure 3 presents the plan view of the benchmark building (Plan1) and its variation (Plan2), while all the case-study structures are summarized in Figure 4.

PLAN 1

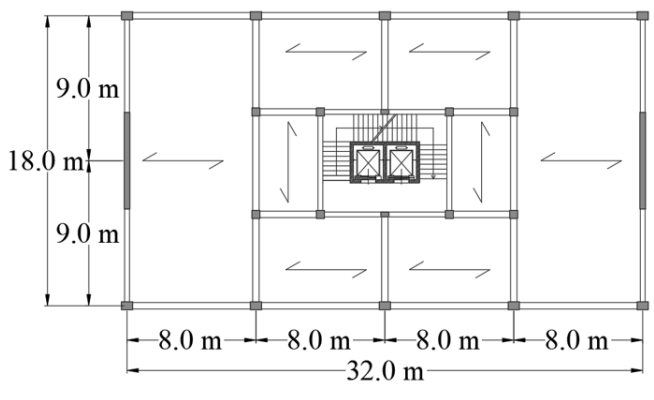

PLAN 2

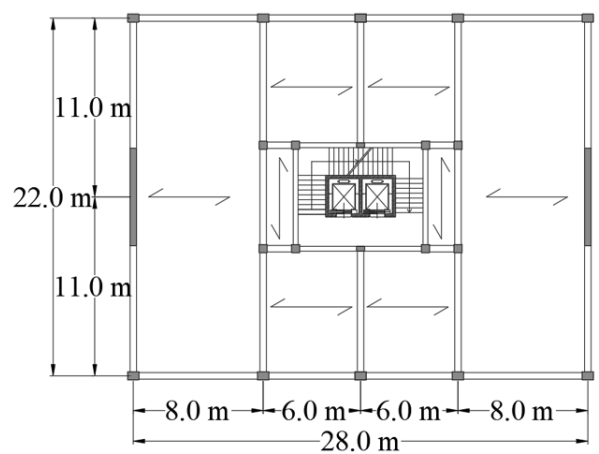

Figure 3: Plan view and dimensions of the benchmark building (left) and modified plan (right).

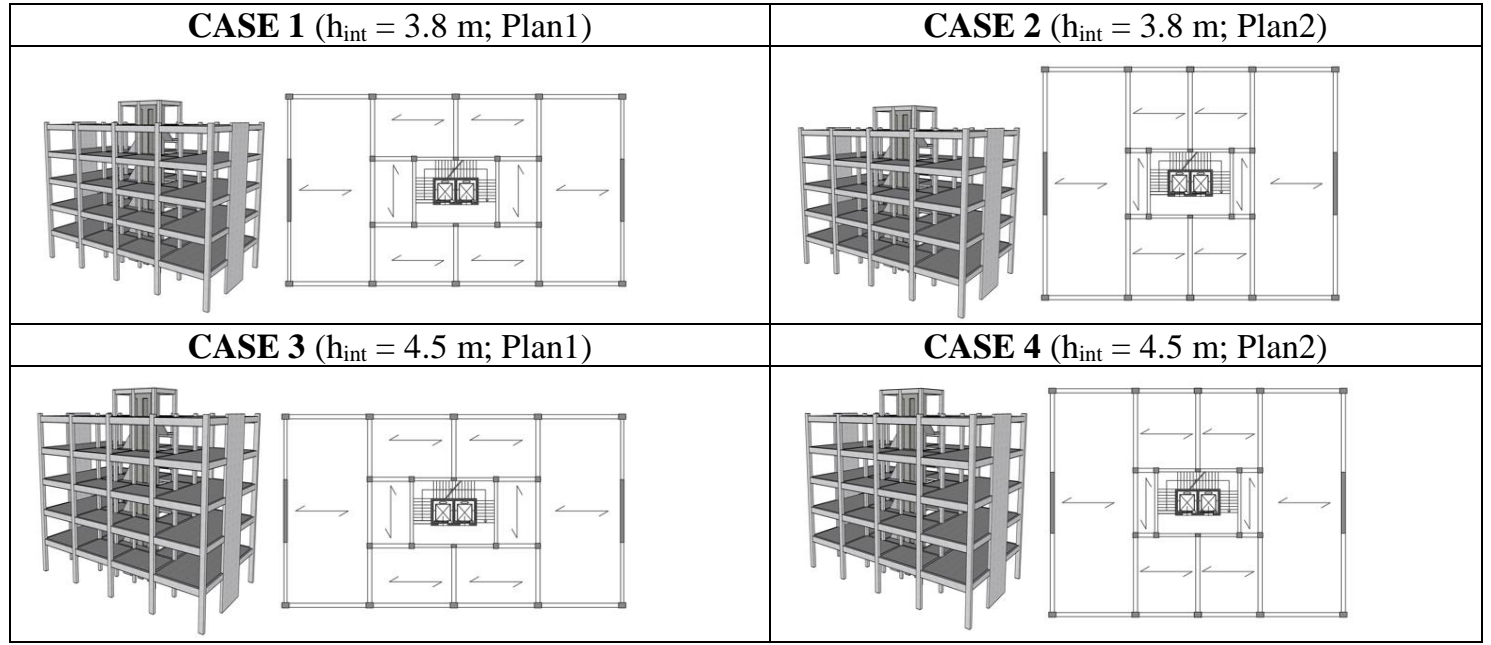

Figure 4: Case-study buildings. 
In terms of dimensions of the structural members: the seismic beams and columns have same dimensions for both building plan $(400 \times 700 \mathrm{~mm}$ and $500 \times 700 \mathrm{~mm}$, respectively); while the wall is $6 \mathrm{~m}$ long, but its thickness varies depending on the plan configuration (350 $\mathrm{mm}$ for Plan1 and $400 \mathrm{~mm}$ for Plan2). Finally, the gravity beams connecting the wall are 300 x $600 \mathrm{~mm}$ and 400 x $700 \mathrm{~mm}$, respectively for Plan 1 and Plan 2.

\subsection{Building design}

Referring to this structural scheme, geometry and related gravity loads, all the buildings are designed following the Direct Displacement Based Design (DDBD) procedure by $[12,13]$. The DDBD procedure has been performed at the ULS limit state (Life-Safety) considering an appropriate value for the inter-storey drift limit, i.e. $2 \%$ for the frame direction and $1.2 \%$ for the wall direction for all case-study structures.

Table 1 shows the DDBD results for all the buildings in terms of yielding displacement $\left(\Delta_{\mathrm{y}}\right)$, design displacement $\left(\Delta_{\mathrm{d}}\right)$, effective mass $\left(\mathrm{m}_{\mathrm{e}}\right)$, effective height $\left(\mathrm{H}_{\mathrm{e}}\right)$, equivalent viscous damping $\left(\xi_{\text {eq }}\right)$, effective period $\left(\mathrm{T}_{\mathrm{e}}\right)$, effective elastic stiffness $\left(\mathrm{K}_{\mathrm{e}}\right)$, and base shear $\left(\mathrm{V}_{\mathrm{b}}\right)$.

\begin{tabular}{lllllllll}
\hline \multirow{2}{*}{ Parameter } & Case 1 & \multicolumn{3}{c}{ Case 2 } & \multicolumn{3}{c}{ Case 3 } & \multicolumn{3}{c}{ Case 4 } \\
& Frame & Wall & Frame & Wall & Frame & Wall & Frame & Wall \\
\hline$\Delta_{\mathrm{y}}[\mathrm{mm}]$ & 62.17 & 50.29 & 62.15 & 50.26 & 73.38 & 70.14 & 73.36 & 70.10 \\
$\Delta_{\mathrm{d}}[\mathrm{mm}]$ & 223.80 & 163.19 & 223.74 & 163.13 & 264.36 & 192.63 & 264.28 & 192.56 \\
$\mathrm{~m}_{\mathrm{e}}[\mathrm{t}]$ & 2760.15 & 2627.80 & 2914.20 & 2774.46 & 2834.12 & 2698.27 & 2991.83 & 2848.42 \\
$\mathrm{H}_{\mathrm{e}}[\mathrm{m}]$ & 13.24 & 13.60 & 13.24 & 13.60 & 15.63 & 16.05 & 15.62 & 16.05 \\
$\xi_{\mathrm{eq}}[\%]$ & 19.19 & 18.35 & 19.19 & 18.35 & 19.19 & 16.90 & 19.19 & 16.90 \\
$\mathrm{~T}_{\mathrm{e}}[\mathrm{s}]$ & 2.65 & 1.91 & 2.65 & 1.91 & 3.13 & 2.22 & 3.13 & 2.21 \\
$\mathrm{~K}_{\mathrm{e}}[\mathrm{kN} / \mathrm{m}]$ & 15533.5 & 28383.0 & 16409.6 & 29987.5 & 11429.8 & 21705.3 & 12072.43 & 22928.2 \\
$\mathrm{~V}_{\mathrm{b}}[\mathrm{kN}]$ & 3476.42 & 4631.94 & 3671.44 & 4891.99 & 3021.56 & 4181.03 & 3190.55 & 4415.01 \\
\hline
\end{tabular}

Table 1: Parameters from the DDBD procedure for all the case-study buildings.

Distributing the base shear obtained by the DDBD throughout each structure, the internal actions in the structural members are determined, and the required steel reinforcement of each component can be designed.

\subsection{Building seismic response}

The building response is initially estimated through the SLaMA procedure described in the NZSEE 2017 Seismic Assessment Guidelines [10]. The seismic design considers capacity design principles, therefore it is sufficient to evaluate the capacity curves related to the beamsway mechanism. In Figure 5 the so-obtained analytical capacity curves are presented for each building and structural direction. The ultimate limit state represents the achievement of the displacement corresponding to the first element reaching the ultimate rotational capacity.

Converting the base shear/displacement relationships into acceleration/displacement responses and considering the demand spectra from the Italian Code [14] of either elastic or ultimate limit states, the building performance points at each intensity level can be identified in the Acceleration Demand Response Spectrum (ADRS) domain. The demand spectra of the ultimate limit states (life-safety SLV and near collapse SLC) have been reduced considering the area-based equivalent viscous damping evaluated through the formulation proposed by Priestley in 2007 [12]. 

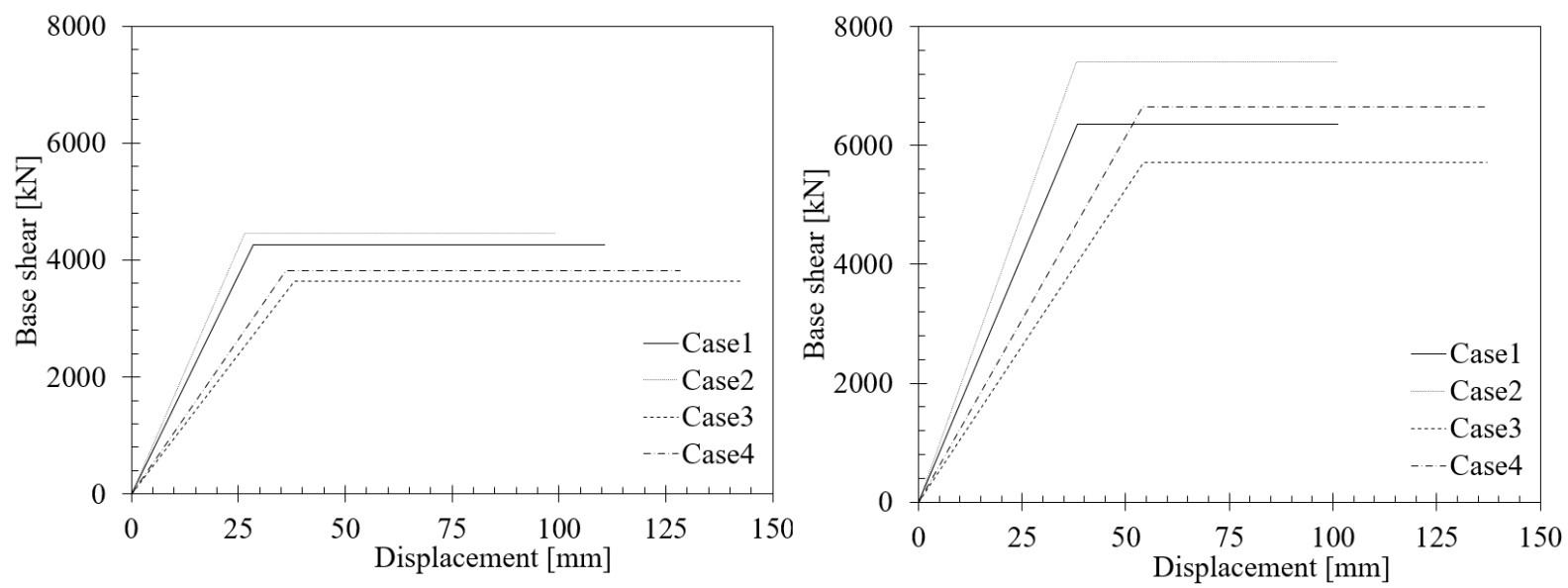

Figure 5: SLaMa-based non-linear (analytical) pushover capacity curves for the case-study buildings. Left: frame direction; Right: wall direction

The SLaMA capacity curves are compared to those obtained from numerical non-linear static analyses. The numerical models of each building are implemented using Ruaumoko 2D analysis program [15] through a lamped-plasticity approach. Therefore, the structural members are represented by elastic components where the non-linearity is concentrated within plastic hinge regions at the end sections (Giberson elements). The plastic hinges are described using proper moment-curvature relationships and a Takeda stiffness-degrading hysteresis rule.

Applying the Capacity Spectrum Method [16], where the area-based equivalent viscous structural damping is directly evaluated from push-pull analyses, the performance points can be also evaluated for this analysis approach.

As example, in Figure 6 can be found a comparison between the push-over curves and performance points obtained from both the analytical and numerical methods.
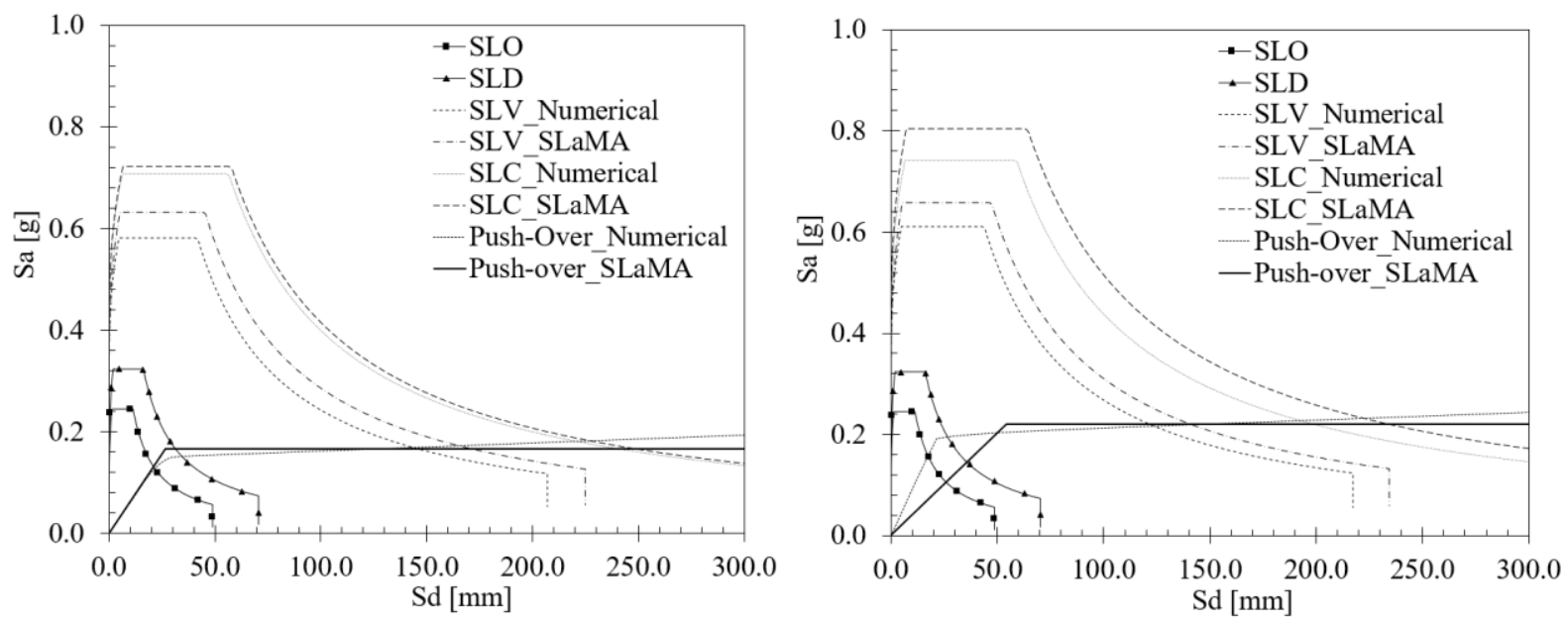

Figure 6: Analytical and numerical capacity curves in the ADRS domain for the Case 2 considering both frame (left) and wall (right) directions.

It can be observed from the previous graphs that the analytical curves well predict the building seismic behavior. The two analyses methods produce very similar performance points for all the case study-buildings in the frame directions, apart from the collapse limit state because of the increasing slope of the numerical curve and the inherent limit of the analytical curve itself which is not modeling the collapse point. Regarding the wall directions, the main differences in the performance points are obtained for the lower limit states (fully opera- 
tional and operational) because of the modeling of the wall as equivalent frame which produces a very high initial stiffness when compared to the one from the analytical procedure.

In order to further validate the accuracy of the SLaMA method as a loss-modeling simplified procedure, non-linear time history analyses are also performed using sets of 7 accelerograms obtained from REXEL [17] for each seismic intensity. The accelerograms, extrapolated from the European Strong Motion database, are, thereby, properly scaled to guarantee the spectro-compatibility to each demand spectrum. For the Life-Safety intensity level, Figure 7 presents the response spectra related to the 7 accelerograms, the average and target spectra, the lower and upper tolerances, as well as the range of periods $(0.15 \mathrm{~s} \div 2 \mathrm{~s})$ selected for the spectro-compatibility to be satisfied.
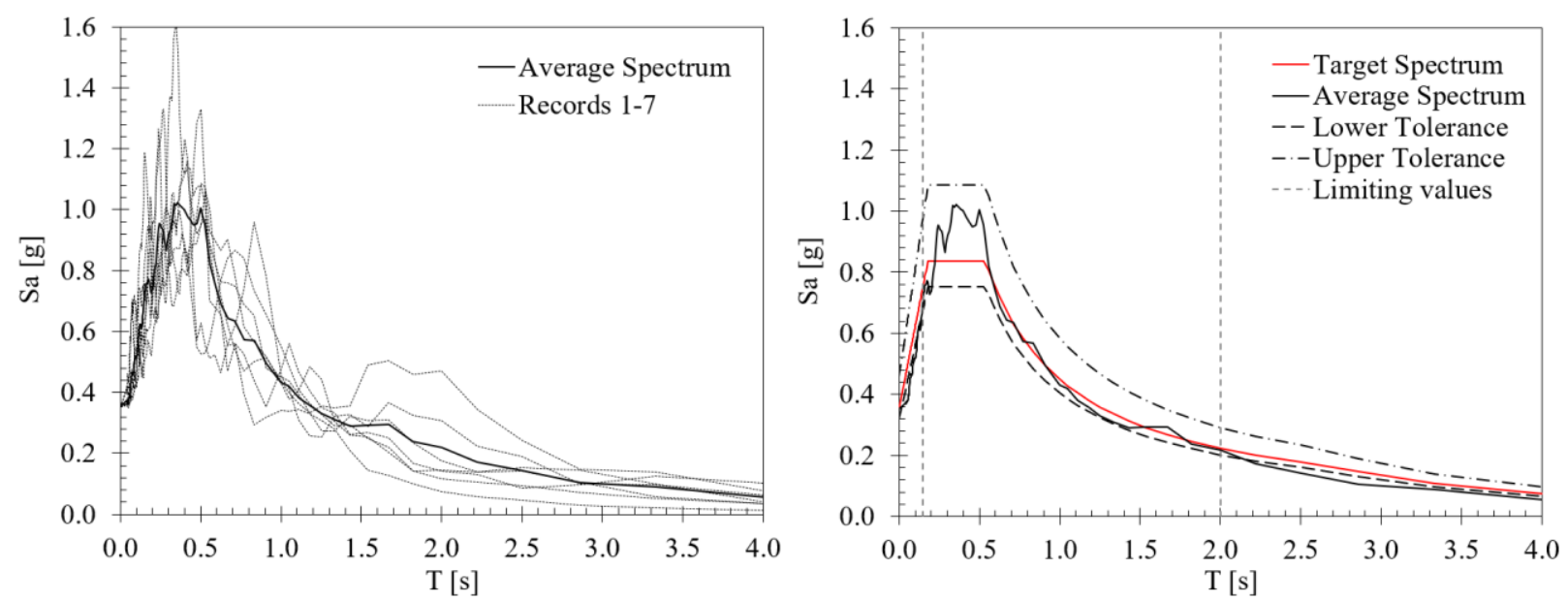

Figure 7: Spectro-compatibility at Life-Safety intensity level.

From time-history analyses a direct estimation of the floor accelerations and inter-storey drift ratios can be determined. As example, the results are presented for one case-study structure and one seismic intensity level in Figure 8. These key engineering demand parameters (EDPs) can be used as direct input data for the loss assessment investigations, while for the analytical and numerical non-linear static assessments they are estimated from the performance points, representing the behavior of the equivalent SDOF system, at each seismic intensity. In fact, considering the effective building height the EDPs at each floor can be estimated assuming proper displacement and acceleration profiles for the SLaMA procedure or the exact profiles determined from the numerical Push-Over results.
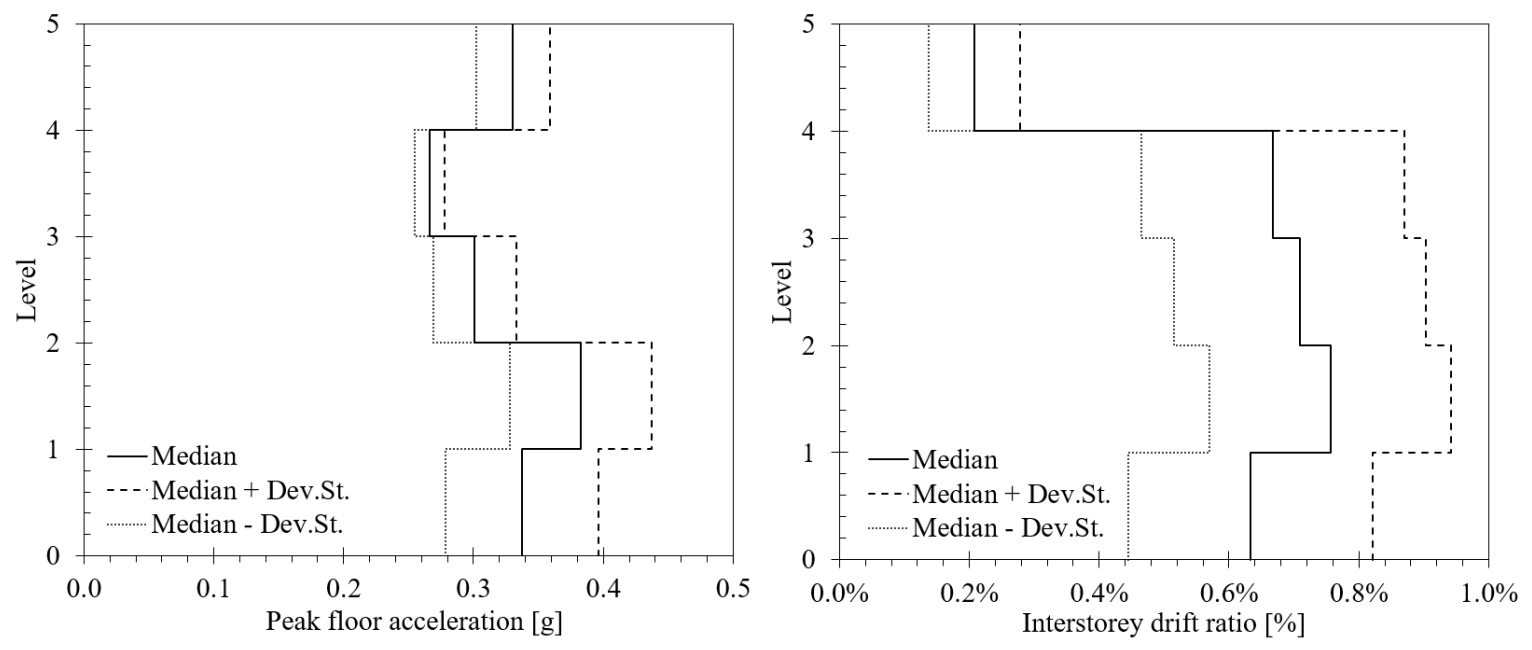

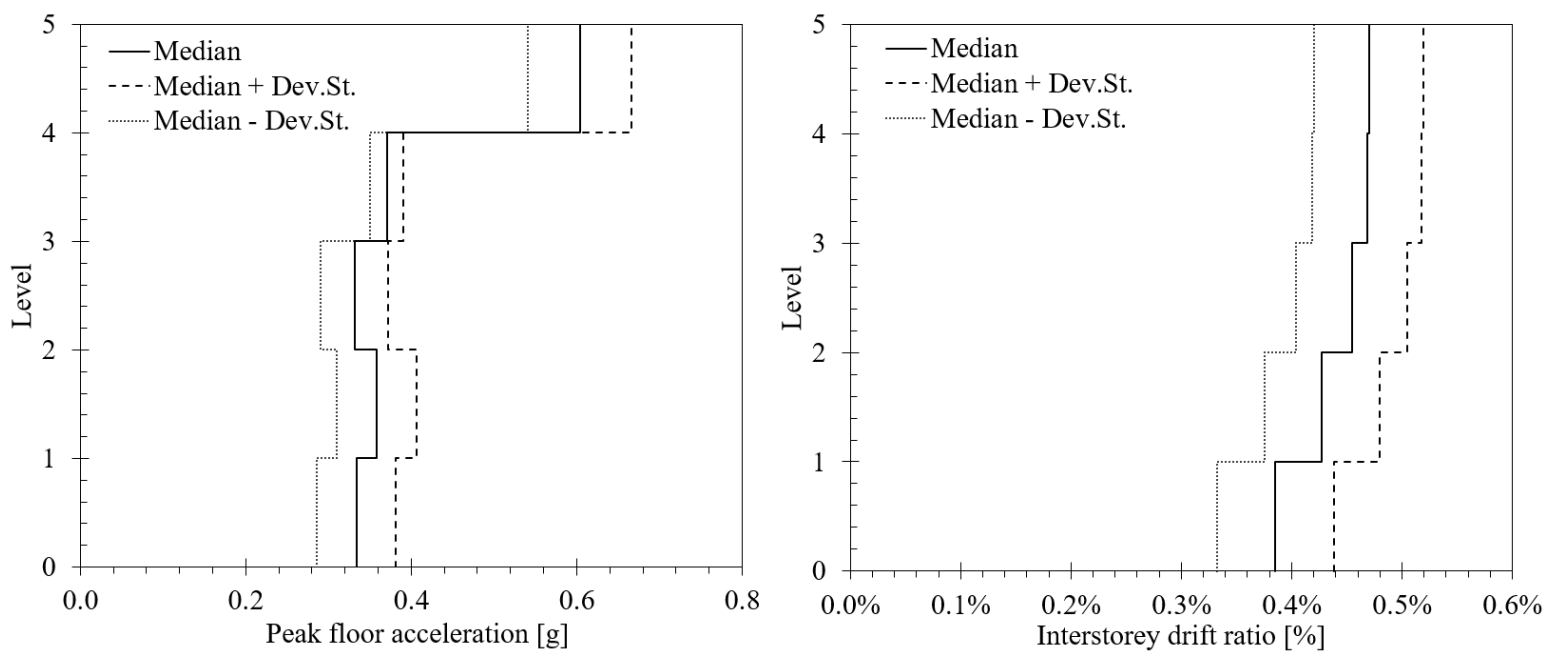

Figure 8: Time-history results for the Life-Safety demand level of Case2: peak floor acceleration and inter-storey drift ratio profiles for both building directions.

\subsection{Loss assessment investigations: SLaMA vs numerical Pushover}

Loss assessment estimations are performed using the PACT software [9] where all the case-study buildings are implemented. The input data for the analysis are: 1) the total replacement cost and time, calculated referring to $338 \mathrm{euro} / \mathrm{m}^{3}$ and estimating the proper number of man-days; 2) the population model of the building, provided by the software depending on the building use; 3) the component fragilities, considering all the structural members, nonstructural components, building services and contents present into the building; 4) the seismic building response, estimated using the different structural analyses methods; 5) finally, the seismic hazard, whose function is built referring to the demand intensity levels reported in the Italian Code [14] $\left(T_{R}=30\right.$ years, fully operational; $T_{R}=50$ years, operational; $T_{R}=475$ years, life-safety; $\mathrm{T}_{\mathrm{R}}=975$ years, near collapse). Regarding the non-structural systems, it is assumed that all the structural skeletons are covered by external curtain walls, while interior components include lightweight partitions, suspended ceilings, electrical and mechanical services and contents. All the structural and non-structural components are defined using the fragility curves and consequence functions already available in the fragility database.

The results obtained for all the case-study buildings are reported in Figure 9 and Table 2.
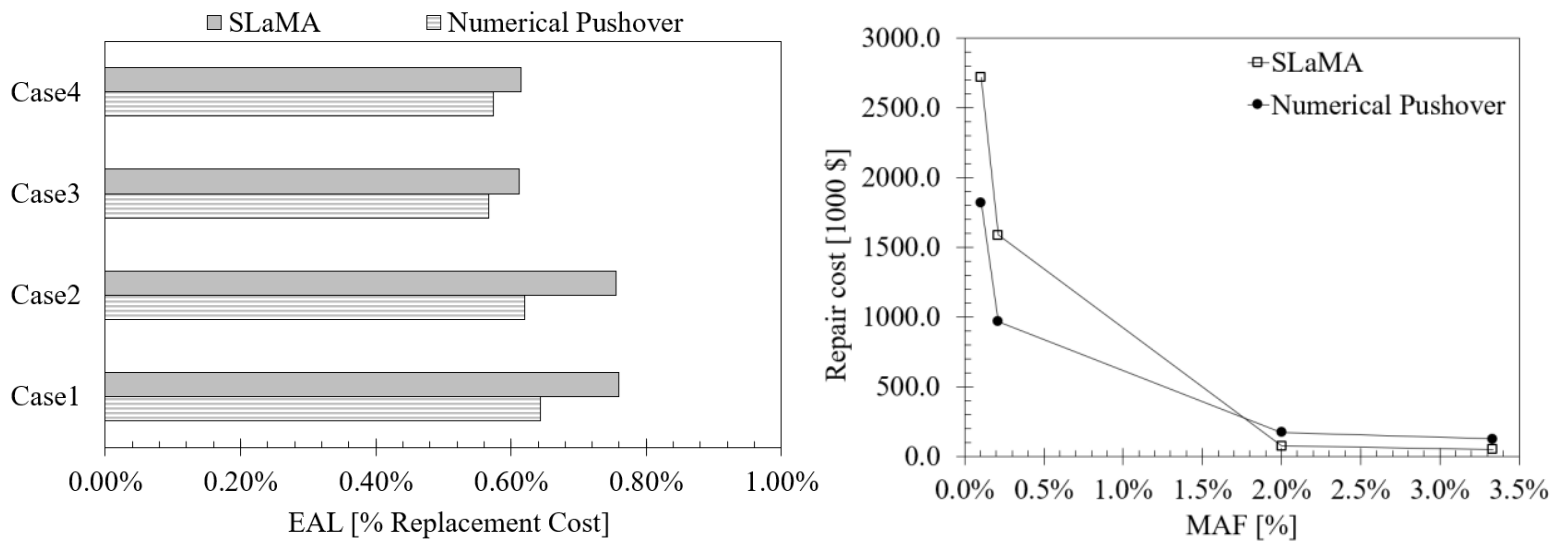

Figure 9: EAL values for all the four case-study buildings considering different structural analysis results (left) and Repair cost/Median Annual Frequency functions (right) for one case-study structure (Case 2). 


\begin{tabular}{lllll}
\hline & Case 1 & Case 2 & Case 3 & Case 4 \\
\hline EAL SLaMA $[\% R C]$ & 0.759 & 0.755 & 0.612 & 0.614 \\
EAL $_{\text {PO }[\% R C]}$ & 0.644 & 0.621 & 0.567 & 0.573 \\
$\Delta$ EAL $_{\text {SLaMA/PO }}$ & 15.16 & 17.79 & 7.31 & 6.70 \\
\hline
\end{tabular}

Table 2: EAL values from non-linear static analyses results: SLaMA versus numerical Pushover (PO).

The loss estimations are carried out considering the floor accelerations and inter-storey drift ratios from: 1) for the SLaMA approach, these parameters are evaluated assuming a proper displacement profile for the building beam-sway mechanism, as suggested in NZSEE Guidelines [10], and considering the floor acceleration profile proposed by FEMA P-58 [9] for simplified procedures, 2) for the numerical analysis, the floor accelerations and interstorey drift ratios are determined from the performance points considering both the displacement and acceleration profiles resulting from the numerical investigation. All the loss estimations have been performed, in this initial validation of the SLaMA procedure, without including the effects of the building collapse fragility or the residual drift into the results.

It can be observed that the application of SLaMA gives quite satisfactory results in terms of Expected Annual Losses (EAL) when compared to the results obtained from the numerical investigations, i.e. approximately $7-18 \%$ higher (conservative side).

Estimations of direct economic losses are also developed through the simplified procedure presented in the 2017 Italian Guidelines for Seismic Risk Classification [18]. This document describes a simple methodology to determine the expected annual losses, that is generally applied for the seismic assessment of existing buildings to investigate the benefits of retrofit strategies and regulate financial incentives provided to private owners to improve the risk/losses of their building. In this research the same approach is applied to new buildings. The building analytical and numerical capacity curves are the starting points of this procedure, which requires the determination of the median annual frequencies, MAF, associated to the achievement of specific limit states in the structure. Particularly, in this study, two limit states (Damage Control and Life-Safety) are identified taking into account just the structural behaviour (achievement of yielding and ultimate rotations of structural members) and used to estimate other limit states related to the structural and non-structural system, as explained in the Guidelines [18].

The results from this simplified methodology are presented in Figure 10 and Table 3.
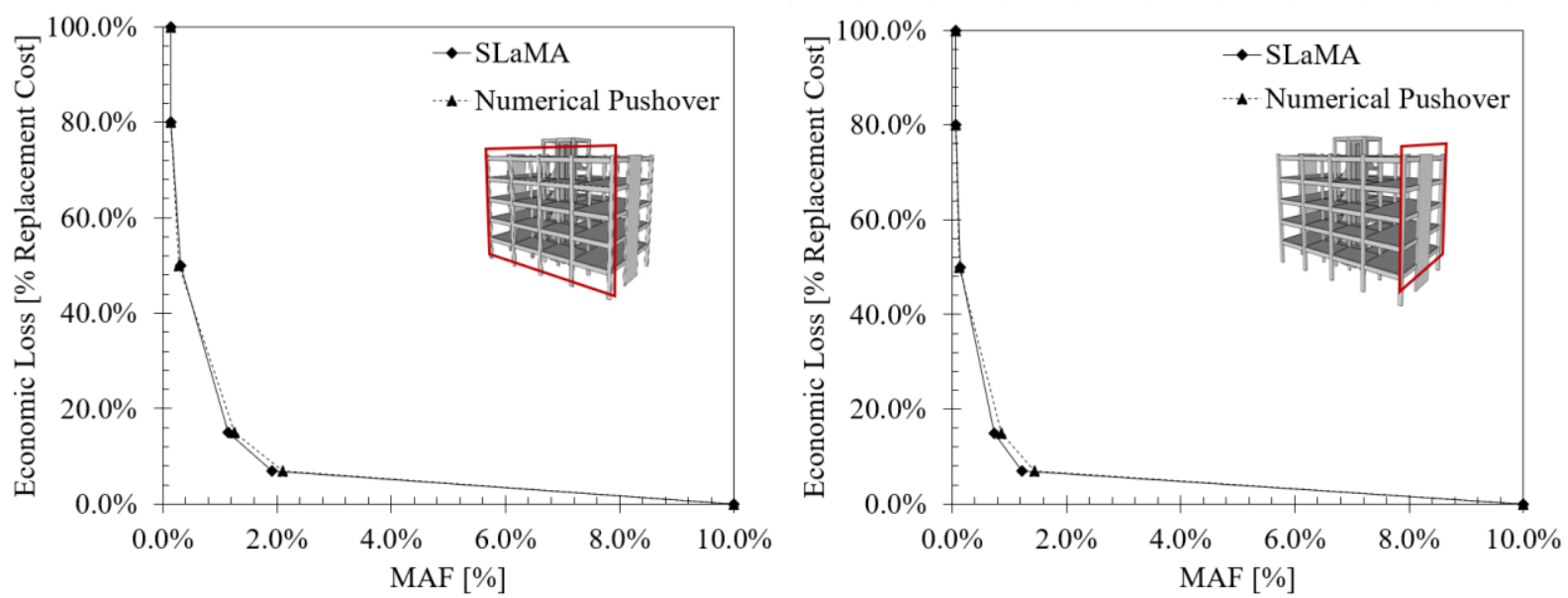

Figure 10: Economic loss/Median Annual Frequency functions estimated following the Italian Guidelines for Seismic Risk Classification [18] for Case 2 and both building directions referring to the capacity curves obtained from SLaMA or numerical studies. 


\begin{tabular}{lllllllll}
\hline & Case 1 & \multicolumn{3}{c}{ Case 2 } & \multicolumn{3}{c}{ Case 3 } & \multicolumn{3}{c}{ Case 4 } \\
\hline & X Dir. & Y Dir. & X Dir. & Y Dir. & X Dir. & Y Dir. & X Dir. & Y Dir. \\
\hline EAL SLaMA [\%RC] & 0.810 & 0.717 & 0.892 & 0.669 & 0.789 & 0.631 & 0.865 & 0.595 \\
EAL PO [\%RC] & 0.872 & 0.749 & 0.920 & 0.704 & 0.849 & 0.648 & 0.891 & 0.623 \\
$\Delta$ EAL PO/SLaMA & 7.17 & 4.22 & 2.99 & 4.94 & 7.27 & 2.68 & 2.91 & 4.49 \\
\hline
\end{tabular}

Table 3: EAL (as a percentage of the Replacement Cost, RC) values from the simplified procedure [18] using the building capacity curves from analytical (SLaMA) and numerical (PO) Pushover analyses.

As it can be observed from the previous table, the differences between the EAL values from the SLaMA-based approach and numerical analysis are minor, in the range of 3-7\% for both building directions. It is also noticed that the EALs associated to the numerical Pushover curves are now higher than those derived from the simplified SLaMA procedure, thus it seems that the estimation is not on the conservative side. This can be justified considering that the elastic and ultimate limit state points are identified on the numerical capacity curves respectively for lower and greater accelerations compared to the same points on the simplified elasto-plastic capacity curves. In any case, the differences are relatively low and well acceptable, thus the SLaMA method can be considered a valuable alterative tool to numerical methods for an initial cost-based building evaluation.

\subsection{Loss assessment investigations: SLaMA vs Pushover vs Time-history}

Loss assessment investigations are finally performed using the results from the timehistory non-linear analyses, therefore the peak floor accelerations and inter-storey drift ratios from all the 7 records of each seismic intensity are directly introduced in the PACT software.

Figure 11 and Table 4 summarize the EAL values obtained from all the structural analysis procedures (analytical push-over, numerical push-over, time-history).

The percentage difference between the EAL values from SLaMA approach and TimeHistory analysis is in the range of $20-40 \%$, while between numerical Pushover and TimeHistory results a difference of $15-30 \%$ is estimated. Notwithstanding the differences between the EAL values from the simplified SLaMA procedure and the sophisticated Time-History investigation are in this case not negligible, the SLaMA method still produces acceptable results and, in any case, more accurate than those obtained when application of linear static analysis suggested within the FEMA P-58 methodology as an alternative simplified investigation compared to the non-linear response history analysis. This statement is based on parallel work being carried out and to be presented in a future companion research publication.
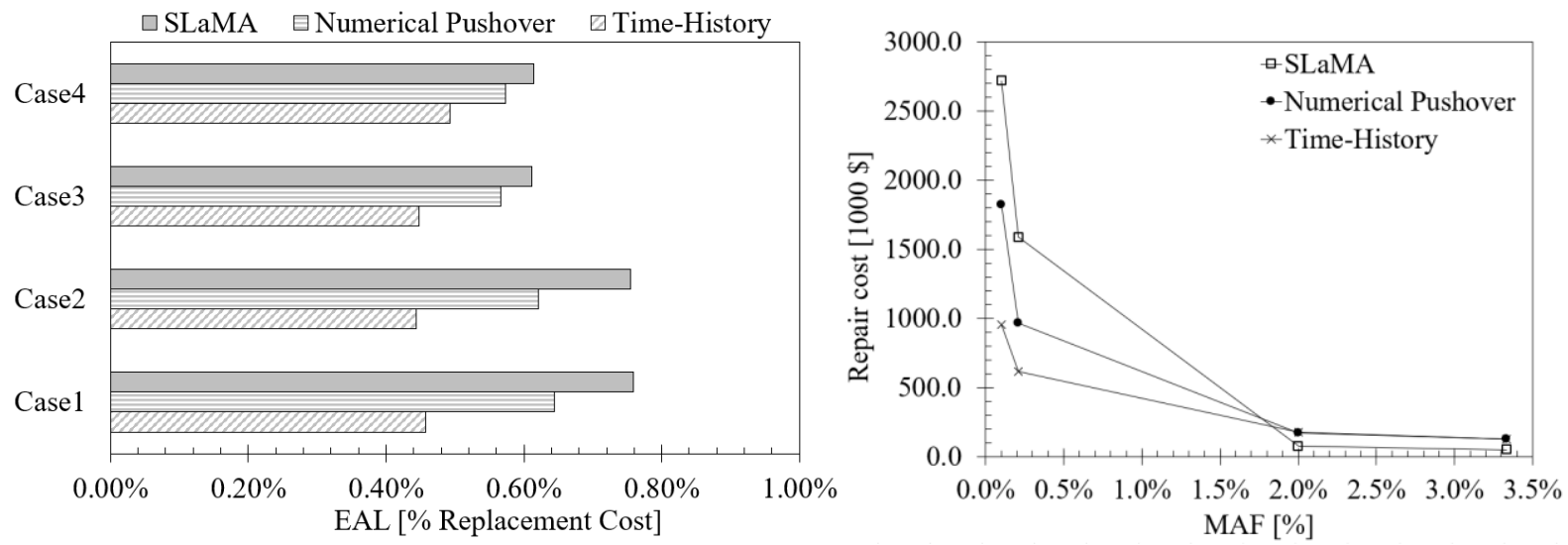

Figure 11: EAL values for all the four case-study buildings considering different structural analysis results (left) and Repair cost/Median Annual Frequency functions (right) for one case-study structure (Case 2). 


\begin{tabular}{|c|c|c|c|c|}
\hline & Case 1 & Case 2 & Case 3 & Case 4 \\
\hline $\mathrm{EAL}_{\mathrm{SLaMA}}[\% \mathrm{RC}]$ & 0.759 & 0.755 & 0.612 & 0.614 \\
\hline $\mathrm{EAL}_{\text {Po }}[\% \mathrm{RC}]$ & 0.644 & 0.621 & 0.567 & 0.573 \\
\hline EAL тн $[\% \mathrm{RC}]$ & 0.457 & 0.444 & 0.447 & 0.493 \\
\hline$\triangle \mathrm{EAL}$ SLaMA / PO & 15.16 & 17.79 & 7.31 & 6.70 \\
\hline$\Delta$ EAL SLaMA / TH & 39.76 & 41.18 & 26.84 & 19.75 \\
\hline$\Delta \mathrm{EAL} \mathrm{PO} / \mathrm{TH}$ & 28.98 & 28.44 & 21.07 & 14.02 \\
\hline
\end{tabular}

Table 4: EAL values from different non-linear analyses results: SLaMA versus numerical Pushover (PO) versus Time-History (TH).

\section{CONCLUSIONS}

In the engineering community the estimation of performance metrics, such as repair costs or downtime, relevant to management decisions for seismic risk mitigation is becoming more consolidated not only for the assessment of existing buildings and thus for the evaluation of optimal retrofit strategy, but also in the seismic design of new buildings.

Probabilistic methodologies have been proposed to implement socio-economic loss estimations, which requires as input data engineering demand parameters, EDPs, such as floor accelerations and inter-storey drift ratios. The latter are usually obtained from simplified linear or non-linear analyses, requiring the implementation of simple or more-sophisticated numerical building models. The more complex the model the more accurate are typically expected to be the results in terms of seismic response, although very time-consuming modeling and analyses are required (i.e. Non-linear Time-History analyses).

With the aim of avoiding the implementation of un-necessary complex numerical models and knowing that non-linear static procedures are a very valuable compromise between accuracy and simplicity, the paper proposes the application of an analytical non-linear static analysis procedure, based on the Simplified Lateral Mechanism Analysis (SLaMA), for the cost/performance-based evaluation of buildings.

The Expected Annual Losses of four case-study reinforced concrete buildings are estimated referring to different structural analyses (SLaMA, numerical Pushover, Time-Histories) and loss assessment methodologies [9, 18]. The results highlighted that the SLaMA-based approach can provide satisfactory and acceptable results when compared to more complex numerical procedures. The method can be a promising tool for the daily use of practicing engineers for a rapid evaluation of the post-earthquake losses and it can be suggested both for the seismic assessment of existing buildings and retrofit interventions as well as part of the design feasibility study of new reinforced concrete structures.

Notwithstanding the good results obtained from this initial study, more investigations are needed to incorporate, for example, the building collapse limit states and the effects of residual drifts, which have been neglected in the loss estimations of this initial work.

\section{REFERENCES}

[1] C.A. Cornell, F. Jalayer, R.O. Hamburger, D.A. Foutch, Probabilistic basis for 2000 SAC Federal Emergency Management Agency steel moment frame guidelines. ASCE Journal of Structural Engineering, 128, 4, 526-533, 2002.

[2] H. Krawinkler, E. Miranda, Performance-based earthquake engineering. Earthquake Engineering: from engineering seismology to performance-based engineering. Bertero VV (eds), CRC Press: Boca Raton, 2004. 
[3] Structural Engineers Associate of California, Performance-based seismic engineering. SEAOC Vision 2000, Sacramento, California, USA, 1995.

[4] Applied Technology Council, Seismic evaluation and retrofit of concrete buildings, Volume 1. Technical Report ATC 40, Redwood City, California, USA, 1996.

[5] Federal Emergency Management Agency, NEHRP Guidelines for Seismic Rehabilitation of Buildings. FEMA-273, Building Seismic Safety Council, Washington, D.C, 1997.

[6] American Society of Civil Engineers, FEMA 356 Prestandard and Commentary for the Seismic Rehabilitation of Buildings. ASCE for the Federal Emergency Management Agency, Washington, D.C., 2000.

[7] J. Moehle and G. Deierlein, A framework methodology for performance-based earthquake engineering. 13 $3^{\text {th }}$ World Conference on Earthquake Engineering (13WCEE), Vancouver, B.C., Canada, August 1-6, 2003.

[8] K.A. Porter, An Overview of PEER's Performance-Based Earthquake Engineering Methodology. $9^{\text {th }}$ International Conference on Applications of Statistics and Probability in Civil Engineering (ICASP9), San Francisco, California, USA, July 6-9, 2003.

[9] Federal Emergency Management Agency, Seismic Performance Assessment of Buildings, Volume 1 - Methodology. Technical Report FEMA-P-58-1, Washington, D.C., USA, 2012.

[10] New Zealand Society for Earthquake Engineering, The Seismic Assessment of Existing Building - Technical Guidelines for Engineering Assessments. NZSEE 2017, New Zealand, 2017.

[11] R.O. Hamburger, Implementing performance based seismic design in structural engineering practice. $11^{\text {th }}$ World Conference on Earthquake Engineering (11WCEE), Acapulco, Mexico, June 23-28, 1996.

[12] M.J.N. Priestley, G.M. Calvi, M.J. Kowalsky, Direct Displacement-Based Seismic Design of Structures. 1st edition, IUSS Press, Pavia, Italy, 2007.

[13] S. Pampanin, D. Marriott, A. Palermo, and New Zealand Concrete Society, PRESSS Design Handbook, Auckland, New Zealand, 2010.

[14] Ministero delle Infrastrutture, Aggiornamento delle Norme Tecniche per le Costruzioni, Suppl. ordinario ${ }^{\circ} 8$ alle G.U. n 42 del 20/02/2018, serie generale, Rome, Italy, 2018.

[15] A.J. Carr, Ruaumoko Program for Inelastic Dynamic Analysis - User Manual, University of Canterbury, Christchurch, New Zealand, 2003.

[16] S.A. Freeman, J.P. Nicoletti, J.V. Tyrell, Evaluations of Existing Buildings for Seismic Risk - A Case Study of Puget Sound Naval Shipyard, Bremerton, Washington. U.S. National Conference on Earthquake Engineering, Ann Arbor, Michigan,18-20 June, 1975.

[17] I. Iervolino, C. Galasso, E. Cosenza, REXEL: computer aided record selection for codebased seismic structural analysis. Bulletin of Earthquake Engineering, 8, 339-362, 2009.

[18] Ministero delle Infrastrutture, Linee guida per la classificazione del rischio sismico delle costruzioni, Decreto Ministeriale 58 del 28/02/2017, Rome, Italy, 2017. 